
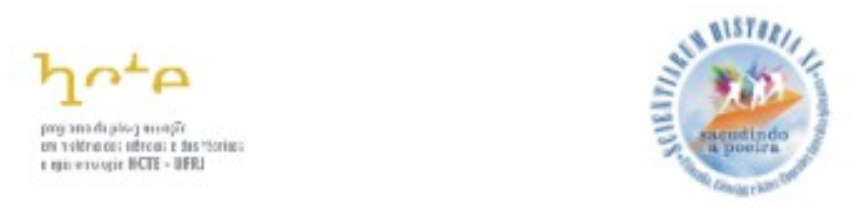

\title{
Seguindo um Robô Submarino por Águas Profundas e Agitadas
}

\section{Following an underwater robot through deep and rough waters}

\author{
João Sérgio S. Assis \\ Programa de Pós-Graduação em História das Ciências e das Técnicas e Epistemologia \\ (HCTE), Universidade Federal do Rio de Janeiro (UFRJ). \\ joao@nce.ufrj.br \\ orcid.org/0000-0002-6005-0689
}

\begin{abstract}
Resumo. Este trabalho reconstrói a história de um robô submarino construído por uma pequena empresa carioca, na década de 1980, financiado pela Petrobras. O robô ficou pronto, foi aprovado e, depois de algum tempo, substituído por outros produtos estrangeiros. A empresa passou a alugar robôs de outros fabricantes para a Petrobras até ser vendida para uma empresa norueguesa. Este trabalho busca não apenas contar uma história do robô, mas mostrar a rede de interesses que atuaram na estabilização e desestabilização deste artefato tecnológico.
\end{abstract}

Palavras Chaves: Águas-Profundas, VOR, PROCAP, Tecnologia-Local.

\begin{abstract}
This work reconstructs the story of an underwater robot built by a small company from Rio de Janeiro, in the 1980s, financed by Petrobras. The robot was build, approved by Petrobras and, after some time of use, replaced by other foreign products. The company stopped building its own robots, beginning to rent robots from other manufacturers to Petrobras. Some time later, the Brazilian company was sold to a Norwegian company. This work seeks not only to tell a story of the robot, but to show the network of interests that acted in the stabilization and destabilization of this technological artifact.
\end{abstract}

Keywords: Deep-Waters, ROV, PROCAP, Local-Technology.

Recebido: 01/10/2018 Aceito: 27/10/2018 Publicado: 05/11/2018

\section{Introdução}


Este trabalho surgiu a partir de um caso que me foi contado por Ivan da Costa Marques, meu orientador, e me levou a questionamentos sobre o quanto do esforço de desenvolvimento tecnológico realizado localmente (nas universidades, nas empresas e através dos órgãos de fomento) resulta em benefícios para o país.

O caso aconteceu numa reunião na UFRJ em 2016, onde a história de um robô foi contada de forma superficial, deixando uma série de lacunas a serem preenchidas por quem se interessasse por ela. A história falava de um robô (que tipo de robô?), desenvolvido por uma empresa nacional (qual empresa?), com financiamento brasileiro (quem financiou?), com alguma participação da COPPE (quando foi isso?). O robô ficou pronto, foi homologado, a empresa foi vendida para uma multinacional e agora o Brasil importa o robô.

Este texto descreve a pesquisa realizada e algumas das histórias que foram utilizadas para preencher estas lacunas e trazer de forma mais detalhada um novo recorte da história do robô. $\mathrm{O}$ objetivo deste trabalho, porém, não é apenas contar uma história "mais completa" de um robô, nem de contar sua história "definitiva". Também não se pretende defender que a empresa que fabricou o robô deveria, ou não, ser vendida.

O que este trabalho se propõe a fazer é, utilizando o ferramental oferecido pela Teoria Ator-Rede, mostrar as relações e interesses que uniram engenheiros, técnicos, empresas, empresário, políticos, planos econômicos, robôs, pressão da coluna d'água e correntes marinhas. Estas relações e interesses contribuíram para estabilizar e manter, por algum tempo, uma "forma”, uma configuração Robô/Empresa/Empresário, que por fim acabou por se desestabilizar e se reconfigurar em uma nova forma.

\section{A Primeira História}

Voltando ao caso inicial, a primeira história do robô surgiu num diálogo que aconteceu numa reunião no Instituto de Biofísica Carlos Chagas Filho, na UFRJ, onde um dos participantes, o professor Luiz Bevilacqua, se dirigiu a Wanderley de Souza, presidente da Finep, e falou de um robô projetado com a ajuda da Coppe para uma empresa brasileira contando com financiamento nacional. O equipamento ficou pronto e foi homologado, mas a empresa foi vendida para uma empresa estrangeira, que agora exporta o robô para o Brasil. Ao final do seu relato, o professor Bevilacqua perguntou a Wanderley de Souza o que poderia ser feito a respeito. Sua resposta foi que nada podia ter sido feito, pois "não seria possivel, pelas leis brasileiras, proibir a venda da empresa". Esta resposta, que serviu para encerrar a discussão, impondo naquele momento um fato consumado e colocando a história do robô em uma "caixa preta".

A fala de Wanderley de Souza foi apresentada entre aspas não por ser uma reprodução literal do que foi dito pelo presidente da Finep, mas para destacar que ela é passível de contestação. "Um enunciado que não tem a necessidade alguma de aspas, de nenhum condicional, tem como particularidade a impossibilidade de distingui-lo do mundo", ou seja, "Fica de alguma forma naturalizado. Não parece de nenhum modo procedente do 
discurso nem como uma etapa particular, talvez sua etapa final" (LATOUR, 2016, p. 78 - grifos do autor).

A proposta deste trabalho é reabrir "caixas pretas" e questionar "naturalizações" que foram feitas acerca da história de um robô. Para reabrir estas caixas pretas devo buscar os interesses, as disputas e os acordos que foram realizados entre pesquisadores, engenheiros, empresários, políticos, órgãos de fomento, robôs e as leis nacionais que permitem a venda e incentivam o desenvolvimento ou a importação de produtos.

Para além do fato de que não sabemos ainda quando esta primeira história ocorreu e que robô é este, esta solução de fechamento deixa muitas questões em aberto e sem reposta: Será esta uma história comum? Será que a tecnologia que vem de uma empresa estrangeira é sempre mais avançada, mais eficiente, mais competitiva? O que é mais avançado? O que é mais eficiente? O que é mais competitivo? O que diferencia uma empresa nacional de uma empresa estrangeira? Que sentido faz um país utilizar seus recursos intelectuais e financeiros para desenvolver uma tecnologia e depois importá-la? O que é possível fazer para manter este produto nas mãos de uma empresa nacional? Será que se deve sempre dar livre curso às ditas "leis do mercado"?

\section{Segunda História}

O primeiro passo deste trabalho foi preencher as lacunas desta história original. Antes de procurar as pessoas envolvidas, realizei uma pesquisa dos robôs de alguma forma ligados a Universidade, construídos por uma empresa que foi posteriormente vendida a uma empresa estrangeira. Deparei-me, então, com a seguinte narrativa que, por simplificação, tratarei de agora em diante como segunda história.

Esta história aparece em uma publicação da Confederação Nacional da Indústria sobre 22 empresas brasileiras que se destacaram pela inovação. No capítulo dedicado à Petrobras e ao seu Programa de Capacitação para Águas Profundas (PROCAP), há um pequeno parágrafo falando em como a Petrobras investiu numa pequena empresa, chamada CONSUB, para produzir o primeiro robô submarino (um VOR ou Veículo de Operação Remota) do Brasil, para substituir mergulhadores em profundidades superiores a 400 metros. A história também conta que a CONSUB foi criada em $1983 \mathrm{e}$ foi vendida para uma companhia norueguesa 18 anos depois.

Duas histórias muitos parecidas. Seriam as mesmas? Como num sistema de muitas equações e variáveis foi possível utilizar uma história para completar a outra. Avançando mais um pouco na determinação das relações que ligam estes dois casos, descobri que o professor Bevilacqua, um dos interlocutores da primeira história, estava conectado a história do robô da segunda história. A Petrobras, na mesma época que contratou a CONSUB, contratou a COPPE para estudar a tecnologia dos robôs submarinos, projeto que foi chefiado pelo professor Bevilacqua. Além disso, teses e artigos da COPPE foram escritos mencionando o robô da CONSUB. 


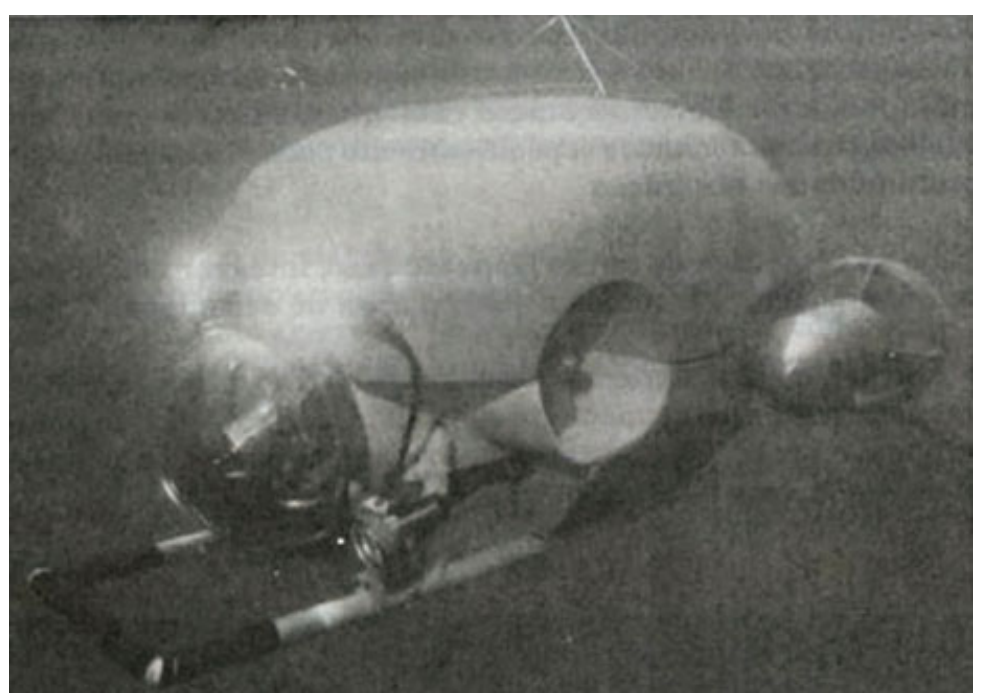

Figura 1. Robô Submarino VCR-01/1000, apelidado “Tatú'”.

Fonte: TEMKE e FERREIRA, 1990, p. 198

Ao buscar a confirmação do professor Bevilacqua, porém, este afirmou que a primeira história era sobre outro robô - um robô desenvolvido por ocasião da Copa do Mundo de 2014. Duas histórias, muito semelhantes, ocorridas em um intervalo de 30 anos. A primeira pergunta (será uma história comum?) parece estar respondida. Sendo assim, optei por continuar seguindo a história do robô submarino CONSUB, apelidado de Tatuí.

\section{O Robô e o PROCAP}

Com estas informações da segunda história descobri que o robô Tatuí (figura 1) foi um dos projetos do programa de capacitação para águas profundas (PROCAP) da Petrobras, realizado entre os anos de 1986 e 1992. Esta relação com o PROCAP me levou à terceira história do robô e também a história mais completa contada até hoje. Esta história se encontra num artigo publicado na Revista Brasileira de Inovação pelos economistas da UNICAMP André Furtado e Adriana Freitas. O artigo, chamado "Nacionalismo e Aprendizagem no Programa de Águas Profundas da Petrobras", faz parte do projeto de pesquisa de André Furtado e seus orientados que foi realizado entre os anos de 1993 e 2004 sobre os três PROCAPs da Petrobras.

Segundo Furtado e Freitas, o Departamento de Perfuração da Petrobras (DEPER) solicitou a construção de um robô de observação, mas o projeto, que já era muito difícil, encontrou uma série de dificuldades técnicas, foi equivocado desde o início e não recebeu todas as correções de rumo necessárias. Apesar disso, os autores afirmam que “O ROR [Robô de Operação Remota] não chegou a ser um fracasso tecnológico, porém foi certamente um fracasso comercial". No entanto, o "fracasso" ficou limitado apenas ao robô. A CONSUB, "graças ao projeto, capacitou-se para atuar no mercado de operação/aluguel de robôs" e que isso "beneficiou a Petrobras, ao baixar o preço do aluguel de robôs no mercado nacional". Além disso, os autores consideram que 
"formaram-se importantes competências em recursos humanos no fabricante nacional e na Petrobras" (FURTADO e FREITAS, 2004, p. 70-71).

"Não houve continuidade nas operações porque a Petrobras mudou a política de compra e passou a alugar os robôs ao invés de adquiri-los" (FURTADO e FREITAS, 2004, p. 70-71). Furtado e Freitas, na sua história do robô, fazem uma divisão entre o tecnológico, o econômico e o político, o que pode levar à conclusão ${ }^{1}$ de que as dificuldades técnicas enfrentadas, e parcialmente resolvidas, pelo projeto do robô levaram ao seu abandono e a substituição por um equipamento importado. Em artigo recente (ASSIS, 2018) defendi que no Brasil a suposta deficiência técnica de um produto tem sido utilizada para encerrar as discussões sobre a viabilidade de um produto, deixando de lado as questões econômicas e/ou políticas. Os estudos CTS têm defendido que as fronteiras entre estas perspectivas (tecnológica, econômica ou política) são difusas ou mesmo inexistentes (LAW, 2018, p. 43).

\section{Robô nos Jornais}

Uma pesquisa detalhada ${ }^{2}$ nos jornais da época revelou uma história diferente. $\mathrm{O}$ primeiro PROCAP - hoje reconhecido como uma história de sucesso (MORAIS, 2013, p. 141, 303) - era desconhecido dos jornais durante boa parte de sua execução (na década de 1980), aparecendo apenas em poucas matérias pagas pela Petrobras. Em 1986, o que se encontra nos jornais é um debate, ocorrendo dentro do governo, se seria mais vantajoso para o país investir na exploração de petróleo em águas profundas, tendo de desenvolver sua própria tecnologia, ou simplesmente aproveitar os preços baixos do petróleo importado ${ }^{3}$. O que este debate esconde é o conflito crescente no país entre a necessidade de estabilização da economia (num ambiente de inflação crescente) e a política de substituição de importações (buscando independência tecnológica) herdada do período de governo militar. A chegada do Plano Cruzado, como sua promessa de estabilizar a economia, encerrou a disputa, garantindo o investimento da Petrobras nas águas profundas e, consequentemente, a existência do PROCAP.

A história do Robô Tatuí nos jornais é inversa. Diversas reportagens foram publicadas ao longo da década de 1980 acompanhando o projeto do "robô submarino que iria ajudar na busca do petróleo". O interesse despertado no público em geral foi potencializado pela grande divulgação, entre 1985 e 1987, das expedições do Woods

\footnotetext{
${ }^{1}$ Outras pessoas que recontaram esta história atribuíram aos problemas técnicos a mudança de política da Petrobras.

${ }^{2}$ Consultei cerca de 150 reportagens, das décadas de 1980 e 1990, publicadas nos jornais O Globo, Jornal do Brasil, Jornal do Commercio e Folha de São Paulo sobre os temas investimentos na exploração de petróleo em águas profundas, PROCAP, robôs submarinos e a CONSUB.
}

${ }^{3}$ No início de 1986 ocorreu o contrachoque do petróleo, invertendo a tendência de aumento do preço do petróleo da década anterior. 
HoleInstitution(WHOI) que localizaram e filmaram os restos do Titanic, que contaram com a utilização de um robô semelhante ao Tatuí, o Jason Jr.. Por coincidência, o oceanógrafo Paulo Mancuso Tupinambá, fundador e presidente da CONSUB, passou uma temporada no Woods HoleInstitution na década de 1970.

Pelas reportagens é possível traçar uma cronologia da história do Tatuí e da CONSUB. A empresa foi contratada pela Petrobras em finais de 1986, em abril de 1987 começou a construir o robô, realizando seus testes iniciais 18 meses depois. Em 1989, o robô entrou em operação e foi aprovado pela Petrobras, em 1991, após mais de 300 operações entre 150 e 400 metros de profundidade. Em 1994, Paulo Tupinambá afirmou que o Tatuí não era mais utilizado pela Petrobras, que a CONSUB não tinha como competir com os preços praticados pelas empresas estrangeiras. Em algum momento de 1997, uma companhia norueguesa comprou $90 \%$ da empresa que passou a se chamar DSND-CONSUB. Paulo Tupinambá vendeu o resto de sua participação na empresa em 2001 .

\section{Ambiente Político e Econômico}

As três histórias, artigos acadêmicos e artigos de jornais e revistas serviram para iluminar a trajetória do robô Tatuí, porém este apanhado não dá conta de descrever as forças e interesses que influenciaram nestes acontecimentos. A história do Robô Tatuí se entrelaça com a história do PROCAP, da Petrobras e do petróleo no Brasil. O petróleo no Brasil, desde o final da Primeira Guerra Mundial foi se configurando como um "projeto nacional" (ASSIS, 2017a, 2017b), mobilizando uma significativa parcela da população. A criação da Petrobras favoreceu aos grupos nacionalistas à medida que e empresa conseguia encontrar mais petróleo e colaborava com a formação de quadros técnicos para apoiar seu trabalho (PEYERL, 2014). Os governos militares após 1964, que enxergavam o petróleo como questão de segurança nacional, sobretudo após o governo Geisel, implementaram uma política de substituição de importações, cujos princípios influenciaram a formação do primeiro PROCAP.

A crescente hegemonia das teses econômicas monetaristas e neoliberais nos países centrais, aliada a crises econômicas persistentes, decorrente dos choques do petróleo e da crise da dívida, foi modificando de forças dentro e fora do governo, desestabilizando o projeto nacional do petróleo. A redemocratização do país e a progressiva perda de influência política dos militares serviram para associar as políticas desenvolvimentistas a desequilíbrio econômico, protecionismo a autoritarismo. Empresas públicas passam a ser associadas à ineficiência, difundindo a ideia de que empresas estatais devem atuar segundo os mesmos critérios de eficiência das privadas. O PROCAP, com seus projetos em pleno desenvolvimento, foi atingido profundamente por estas mudanças, o que fez com que os investimentos em desenvolvimento de tecnologia não resultassem em produtos efetivamente utilizados pela companhia. 


\section{Considerações Finais}

O trabalho de Furtado e Freitas (2014) não se limitou ao robô Tatuí, tendo abordado também mais seis projetos do PROCAP, selecionados por terem sido desenvolvidos por pesquisadores brasileiros. Em pelo menos cinco destes trabalhos o destino foi o mesmo do robô Tatuí: desenvolvimento de tecnologia nacional que, pelos mais variados motivos, não foi aproveitada pela Petrobras.

O Robô Tatuí não foi um caso isolado, e todos estes "fracassos" se devem mais a uma mudança de orientação político/econômica do país e da própria Petrobras do que de deficiências tecnológicas destes produtos.

Como continuação do trabalho foram realizadas entrevistas com Paulo Mancuso Tupinambá, fundador e presidente da CONSUB, e com Ney Robson Salvi dos Reis, atual chefe da equipe de robótica da Petrobras e que entrou na empresa para acompanhar o desenvolvimento do Robô Tatuí.

Por falta de espaço neste texto não foi possível aprofundar as ligações existentes entre os grupos de robótica da COPPE e da Petrobras durante o desenvolvimento do robô. Tampouco foi possível aprofundar a história de Paulo Tupinambá, antes, durante e depois do Tatuí, onde se percebem como se misturam e se confundem as histórias do empresário, da empresa e do robô. Estes assuntos foram abordados mais profundamente na minha tese de doutorado que se encontra em fase final de elaboração.

\section{Referências}

ASSIS, J. S. S.. Tecnologia Local no Projeto Nacional do Petróleo. In: $7^{\circ}$ Simpósio Nacional de Ciência, Tecnologia e Sociedade - Esocite.br/Tecsoc, 2017, Brasília. Anais do $7^{\circ}$ Simpósio Nacional de Ciência, Tecnologia e Sociedade, 2017 a.

ASSIS, J. S. S.. Construção e Desestabilização do "Projeto Nacional" do Petróleo. In: Scientiarum Historia X, Rio de Janeiro. Anais do Scientiarum Historia X, 2017b.

ASSIS, J. S. S. Sucesso/Fracasso de um Produto Tecnológico Segundo Diversas Perspectivas: Um Robô no Brasil dos Anos 1980. Comunicação Oral. XII Jornadas Latinoamericanas de estudos sociales de laciencia y la tecnologia. Santiago de Chile. Julho, 2018

CNI. Inovação em cadeias de valor de grandes empresas: 22 casos. Brasília: CNI : IEL, 2013. 464 p. ISBN 978-85-7957-099-5

LAW, J.. STS as Method. In.: The Handbook of Science and Technology Studies. FourthEdition. The MIT Press. 2017. P. 31-57 
FURTADO, A. T., FREITAS, A. G. Nacionalismo e Aprendizagem no Programa de Águas Profundas da Petrobras. Revista Brasileira de Inovação. Vol. 3 N. 1. Janeiro / Junho 2004. P. 55-86

LATOUR, B. Cogitamus: Seis cartas sobre as humanidades científicas. Tradução de Jamille Pinheiro Dias. São Paulo: Editora 34. 2016. 216 p.

MORAIS, J. M. Petróleo em águas profundas: uma história tecnológica da Petrobras na exploração e produção offshore. Brasília: Ipea: Petrobras, 2013. 424 p.

PEYERL, D. A contribuição do Conselho Nacional do Petróleo e da Petrobras na formação de profissionais para a exploração do petróleo no Brasil. Tese de Doutorado. Campinas: Instituto de Geociências da Unicamp. 2014. 290 p.

TEMKE, C. J. ; FERREIRA, S. R. O Desenvolvimento do Primeiro Veículo de Controle Remoto Submarino Latino Americano. Pesquisa Naval, Número 3, Outubro 1990. p. 195-209. 